
\title{
WHEN USING KNOWLEDGE CAN HURT
PERFORMANCE: THE VALUE OF ORGANIZATIONAL
CAPABILITIES IN A MANAGEMENT CONSULTING
COMPANY
} MARTINE R. HAAS ${ }^{*}$ and MORTEN T. HANSEN ${ }^{2}$

${ }^{1}$ School of Industrial and Labor Relations, Cornell University, Ithaca, New York, U.S.A.

${ }_{2}$ INSEAD, Fontainebleau, France

\begin{abstract}
This paper explores the possibility that utilizing the firm's knowledge resources to complete important tasks can backfire and undermine competitive performance. Drawing on organizational capabilities and knowledge-sharing research, we develop a situated performance view that holds that the value of obtaining and using knowledge within a firm depends on the task situation. Using a data set of 182 sales proposals for client work in a management consulting company, we show that sales teams that had varying needs to learn and differentiate themselves from competitors derived different levels of value from obtaining and using electronic documents and advice from colleagues. Highly experienced teams were more likely than inexperienced teams to lose the sales bids if they utilized such knowledge. Teams that had a high need to differentiate themselves from competitors also had a lower chance of winning if they utilized electronic documents. There were situations, however, where teams performed better if they utilized the firm's knowledge resources. These results suggest that competitive performance depends not on how much firms know but on how they use what they know. Copyright (C) 2004 John Wiley \& Sons, Ltd.
\end{abstract}

A firm's ability to apply its capabilities in the form of knowledge resources to perform important activities is increasingly viewed as a critical source of competitive advantage in many industries (e.g., Kogut and Zander, 1992; Grant, 1996; Teece, Pisano, and Shuen, 1997). Although employees can benefit from obtaining and using knowledge that exists in other parts of the firm to perform competitive tasks, sharing knowledge across subunits within a firm can be problematic and risky. Employees may find it difficult to search for relevant knowledge (e.g., Ancona and Caldwell, 1992; Cummings, 2004), transfer complex knowledge across organization subunits (e.g., Szulanski, 2000;

Keywords: knowledge sharing; knowledge transfer; organizational capabilities; management consulting; competitive bidding

*Correspondence to: Martine R. Haas, School of Industrial Relations, Cornell University, Ives Hall 365, Ithaca, NY 14853, U.S.A. E-mail: martine_haas@cornell.edu
Reagans and McEvily, 2003), integrate knowledge in groups (e.g., Okhuysen and Eisenhardt, 2002), act on acquired knowledge (e.g., Pfeffer and Sutton, 1999), offer a unique value proposition by reusing knowledge (e.g., Hansen, Nohria, and Tierney, 1999), or protect the firm's knowledge from imitation by competitors (e.g., Teece, 1986; McEvily and Chakravarthy, 2002). Because these problems and risks can outweigh the potential benefits of utilizing the firm's knowledge resources, obtaining and using knowledge from documents or experts in the firm may sometimes impede rather than improve the performance of important tasks. If the anticipated value of knowledge is often difficult to realize, when does knowledge sharing within a firm undermine the firm's competitive performance?

To address this question, we develop a situated performance perspective on the value of knowledge in firms. This perspective emphasizes that the 
value of obtaining and using knowledge should be assessed by evaluating the impact of that knowledge use on the performance of critical tasks, rather than by measuring the quantity of knowledge stocks possessed by the firm or the level of knowledge flows within the firm (cf. Dierickx and Cool, 1989). In addition, this perspective proposes that the value of knowledge can only be properly assessed by studying the task context in which it is used (cf. Collis, 1994; Tyre and von Hippel, 1997; Orlikowski, 2002). We focus on two important characteristics of the task situation that are likely to influence whether utilizing the firm's knowledge resources enhances or undermines task performance: the extent to which the task-performing unit needs to learn from others, and the extent to which it needs to differentiate itself from competitors.

We used the situated performance perspective to examine whether sales teams in a management consulting company enhanced their competitive performance by obtaining and using knowledge from other parts of the firm. These sales teams were bidding for contracts to provide technical analysis, strategy advice, information system implementation, or other business services to corporate clients. As the task units assigned to develop and present sales proposals to potential clients, sales teams routinely sought knowledge from sources outside the team. We examined the utilization of both codified knowledge, which is recorded in written documents and obtained through the firm's electronic database systems, and personal knowledge, which takes the form of expertise held by individuals who do not belong to the team and is obtained through interpersonal networks. Thus, 'knowledge utilization' in this paper refers to the process of obtaining and using knowledge from documents and people outside the team.

\section{FROM KNOWLEDGE STOCKS AND FLOWS TO SITUATED PERFORMANCE}

The situated performance perspective on the value of knowledge builds on but also extends prior research, which can be characterized as typically presenting either a 'stocks' or a 'flows' view of the value of a firm's knowledge (cf. Dierickx and Cool, 1989). The knowledge stocks view suggests that a firm's level of knowledge assets is associated with the firm's economic value or performance. Accounting research, for example, aims to quantify a firm's aggregate levels of knowledge in ways that would allow them to be reported on a balance sheet, like physical assets (e.g., Lev, 2001; Blair and Wallman, 2001). This approach assumes that the value of a firm's knowledge is greater if the firm scores higher on some index of knowledge asset measures, such as the number of experts per area or the number of documents available in an electronic database system (e.g., Skandia, 1998; Davenport and Hansen, 1999). Extending this approach to examine performance outcomes, research on knowledge as an organizational capability has analyzed the relationship between aggregate firm-level measures of knowledge assets and firm-level performance (e.g., Bierly and Chakrabarti, 1996; DeCarolis and Deeds, 1999). Scholars in this tradition have also demonstrated that firm-level knowledge that is tacit and rare enables differentiation from competitors because it is difficult to imitate, leading to higher firm-level performance (e.g., McEvily and Chakravarthy, 2002). These approaches have made progress in assessing the value of a firm's knowledge, but they tend to view knowledge as a property of the overall firm, rather than of individual members or task units. This level of analysis does not explain the variance in the value that different task units within a firm can gain by obtaining and using the firm's knowledge, thus offering limited insight into the question of how utilizing knowledge translates into competitive performance for task units in the firm.

In contrast, other scholars focus on knowledge flows between employees in firms, through informal personal connections or electronic knowledge management systems (e.g., Athanassiou and Nigh, 1999; Gupta and Govindarajan, 2000; Schulz, 2003). Transferring knowledge from one unit to another in a firm can enable organization members to exploit lessons that have been learned in previous work by exchanging information and advice through informal communities of practice (Brown and Duguid, 1991; Lave and Wenger, 1993), solve technical problems more effectively by comparing experiences and telling stories (Orr, 1996), benefit from the firm's best practices (Szulanski, 1996), and explore new ideas and develop creative solutions through brainstorming (Sutton 
and Hargadon, 1996). Yet the acquisition of knowledge from electronic databases or from experts in other parts of the firm is often impeded by cognitive, social, or structural barriers (e.g., Gupta and Govindarajan, 2000; Hansen and Haas, 2001). Although such impediments to knowledge sharing are widely recognized, research on knowledge flows between task units in firms tends to emphasize the processes of knowledge sharing without explicitly considering whether the potential difficulties and drawbacks of knowledge sharing outweigh the potential benefits. This approach therefore does not shed much light on the net effects of knowledge sharing on task-level performance outcomes such as task efficiency, quality, or competitive impact.

Existing research addressing the question of when knowledge is valuable therefore tends to focus on either firm-level performance or interunit transfers, but there is little research examining the effects of inter-unit knowledge transfers on task-unit performance (for some exceptions, see Ancona and Caldwell, 1992; Darr, Argote, and Epple, 1995; Das, 2003; Hansen, 1999). These limitations of the stocks- and flows-based approaches to assessing the value of a firm's knowledge can be addressed through a situated performance perspective in which knowledge is seen as an information good that has value in use, rather than as an economic good that has value in an exchange (cf. Arrow, 1974; Glazer, 1998). The situated performance perspective is grounded in sociological theories of practice that conceive of knowledge neither as a philosophical concept or an abstract cognitive representation (Rorty, 1979), nor as a structure, object, or routine (Nelson and Winter, 1982). Instead, this pragmatic view proposes that knowledge must be demonstrated through its effects on performance in particular task situations (cf. Dewey, 1938; James, 1963; Pentland, 1992). The first premise of a situated performance perspective on knowledge utilization, therefore, is that the value of the firm's knowledge resources must be assessed by examining task performance outcomes, rather than by measuring the levels of stocks or flows of knowledge in the organization. The second premise is that the conditions under which a task is undertaken will moderate the effects of obtaining and using knowledge for that task. Specifically, we propose that when the taskperforming unit has relatively little experience with the task at hand, it has a greater need to learn from others, and that when it faces a highly competitive situation, it has a greater need to differentiate itself from its competitors. These needs for learning and differentiation are likely to vary among task units in a firm and to substantially influence the value of obtaining and using codified and personal knowledge to perform critical organizational tasks. The relationships that we examine between knowledge utilization and task performance are shown in Figure 1. In the next section, we develop predictions about the nature of these relationships in the context of the management consulting industry, where sales teams engage in competitive bidding for new client contracts.

\section{HYPOTHESES}

Knowledge sharing would seem to offer substantial potential benefits for task units in the management

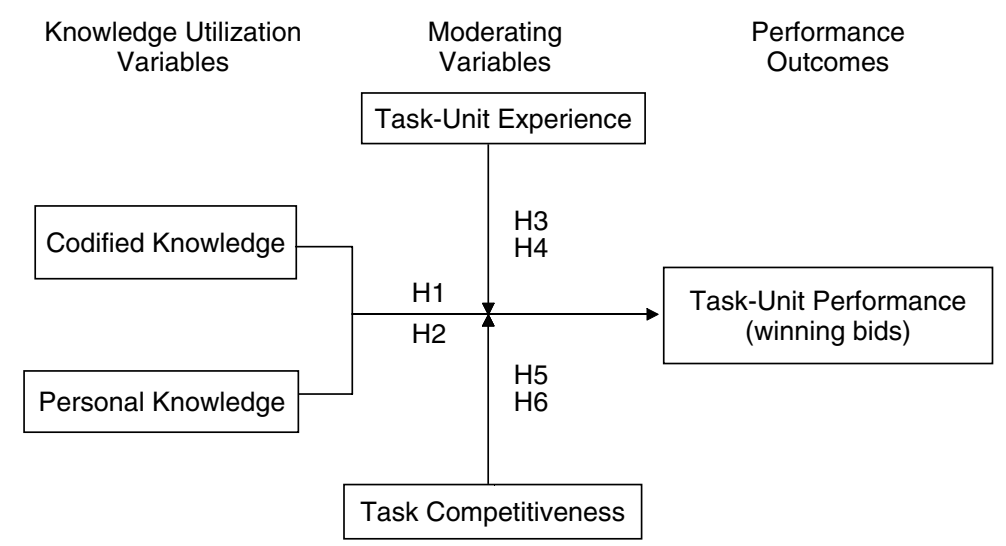

Figure 1. A situated performance view of the effects of utilizing the firm's knowledge on task-unit performance 
consulting industry. Teams that are preparing bids for new client contracts in a management consulting firm face two main challenges in developing a sales proposal. First, the team members must assess the general context in which the potential client operates, including characteristics of its competitive environment, such as market size and share, major competitors, and industry trends. Second, they must analyze the client's particular problem and develop a compelling plan for how to approach and solve that problem. Both codified knowledge, in the form of electronic documents, and personal knowledge, in the form of advice and insights from expert colleagues outside the team, can offer potential benefits to teams engaged in these tasks.

Sales teams that obtain codified knowledge by downloading documents from an electronic database can save themselves from having to undertake time-consuming basic data gathering and analysis. For example, such documents may enable them to reuse information from previous projects, such as analyses of industry profitability, or apply best practices or lessons learned from past projects, such as how to assess a joint venture's potential realistically (cf. Winter and Szulanski, 2001). Sales teams also can benefit from accessing personal knowledge by calling up or meeting with colleagues from other parts of the organization who are not on the team but are experts in the area of the bid. Brainstorming with experts can provide opportunities for the team members to try out tentative ideas or discuss difficult issues. Even if the experts have limited direct experience with the issues faced by the client, they may have analogous experiences that can spark new insights and help the team to come up with innovative ways to tackle new problems (Sutton and Hargadon, 1996; Hargadon and Sutton, 1997). In short, utilizing personal and codified knowledge from outside the team may be helpful for sales teams in preparing their bids. As baseline hypotheses, we therefore predict:

Hypothesis 1: The more codified knowledge utilized by a team, the higher its chances of winning the bid.

Hypothesis 2: The more personal knowledge utilized by a team, the higher its chances of winning the bid.

\section{The moderating effects of team task experience}

\section{Learning benefits}

The potential benefits of obtaining and using codified and personal knowledge from others in the firm are greater when teams are less experienced in the area of the task. Less experienced teams have a greater need to learn than experienced ones and therefore may benefit more from using electronic documents to help them get up to speed on the issues and possible directions for the sales proposal and find out about best practices and lessons from other similar projects. Even in situations in which the firm overall does not have much expertise in the specific requirements of the bid, there are likely to be documents covering background information for the task, such as industry reports and company materials. Similarly, less experienced teams can take advantage of discussions with experts to obtain advice on problems and think through potential solutions.

The value of electronic documents and colleagues' input will be lower, however, for more experienced teams that have less need to learn from others. Such teams are likely to be already familiar with the basic information that is available from electronic documents. Talking to fellow experts from outside the team might occasionally provide new insights or ideas that the team members had not considered before, but these are likely to be much rarer for experienced teams than for inexperienced ones. The implication is that the use of knowledge from outside the team will be less valuable for experienced than inexperienced teams, due to their lower learning needs.

\section{Search and transfer costs}

If only the benefits of knowledge utilization are taken into account, we might expect that the performance of a sales team would not be harmed when the team members obtained and used knowledge from other parts of the firm, even if it was not helped much by such activities because the team was already very experienced in the area of the task. But this assumption overlooks the likelihood that teams will incur opportunity costs when they obtain knowledge: time spent searching for and transferring knowledge from sources outside 
the team takes away time from working on other aspects of the sales proposal, such as developing innovative solutions that are customized to the client. Such opportunity costs are likely to be substantial in the management consulting industry, since time pressures usually are intense due to the tight deadlines imposed on delivering sales bids.

If little relevant codified knowledge exists in the firm's electronic database system, a team may spend considerable time searching through irrelevant documents to identify any that contain relevant information. When large quantities of relevant documents are available, in contrast, teams are likely to have to spend considerable time scanning them in order to identify parts that are of sufficiently high quality to be useful (Hansen and Haas, 2001). Furthermore, to transfer the codified knowledge they find into their work, the team members must carefully read, synthesize, and rework the information in the documents to meet their task requirements (Huber and Daft, 1987).

Likewise, seeking information and advice from colleagues also involves search costs, since the team members may need to contact several people to find experts who are able to provide useful inputs and then secure those experts' cooperation. Slow responses from experts may cause delays in the development of the sales proposal when the completion of critical tasks is contingent on contributions from these experts, impeding the team's progress and potentially harming the quality of the final proposal. In addition, teams may encounter impediments to the transfer of personal knowledge from colleagues, perhaps due to a lack of familiarity or trust between the parties (Uzzi, 1997) or to the difficulty of articulating knowledge that is tacit and incorporating it into new proposals (Hansen, 1999).

Incurring such search and transfer costs is worthwhile if there is substantial learning to be gained from utilizing the knowledge. But when the learning benefits are marginal or negligible because the team is already experienced in the area of the task, there is a risk that obtaining and using more knowledge from documents and colleagues may impede the team's performance. While the knowledge the team obtains is likely to be redundant, the search and transfer activities required still create opportunity costs in the form of time and energy that could be spent instead on improving the quality of the bid (cf. Darr et al., 1995). ${ }^{1}$ Thus, the performance benefits of obtaining and using knowledge from others in the organization are likely to depend on the team's level of task experience. As team task experience increases, the benefits of utilizing knowledge from outside the team decrease. Stated formally:

\section{Hypothesis 3: With an increase in a team's level of task experience, an increase in the amount of codified knowledge utilized reduces the team's chances of winning the bid.}

Hypothesis 4: With an increase in a team's level of task experience, an increase in the amount of personal knowledge utilized reduces the team's chances of winning the bid.

These hypotheses focus on the interactions between knowledge utilization and team task experience, but they do not specify whether the net effects of obtaining and using codified or personal knowledge will be positive or negative. If the main effects of utilizing codified and personal knowledge are positive, as predicted in Hypotheses 1 and 2 , but the interaction effects with team task experience are negative, as predicted in Hypotheses 3 and 4, then the net effects of utilizing codified and personal knowledge on team performance will depend on the relative magnitudes of the main and interaction effects in a particular empirical setting.

\section{The moderating effects of task competitiveness}

When competition for a client contract is intense, developing a sales proposal that distinguishes the focal team from rival sales teams in other firms becomes critical to winning the bid, but codified and personal knowledge may differ in their capacity to differentiate the team from its competitors. Assuming that a team confronts a more competitive task situation to the extent that more firms are

\footnotetext{
${ }^{1}$ The search and transfer costs incurred in obtaining and using personal and codified knowledge may be somewhat lower for more experienced teams, perhaps because they can locate relevant knowledge sources more rapidly, have greater absorptive capacity (cf. Cohen and Levinthal, 1990), or can avoid major distortions and misinterpretations of the knowledge they access (cf. Huber, 1991). Nevertheless, even very experienced teams are not likely to be able to eliminate search and transfer costs entirely, implying that these costs may affect the team negatively in situations where the knowledge obtained and used does not provide any benefits
} 
bidding for the same contract, we measure task competitiveness as the number of competing consulting firms that a focal team faces when bidding for a new client contract.

\section{Codified knowledge and number of competitors}

Obtaining and using codified knowledge can allow team members to address relatively straightforward issues in the sales proposal more easily, because they can reuse existing material that applies to multiple proposals. However, because the knowledge contained in electronic documents usually is simplified and generalized during its conversion to document form to make it more widely applicable, it is unlikely to be rich enough or sufficiently specific to the client's situation to help the team with the challenge of developing the highly customized solution that a successful sales bid demands (cf. Daft and Lengel, 1984).

The risk that a focal team will not be able to differentiate itself with the knowledge it gains from electronic documents may increase as the number of competing bidders increases, for two reasons. First, the observation that codified knowledge is relatively easy to capture and transfer suggests that other firms probably have documents similar to those of the focal firm. This may happen because the focal firm's documents are imitated by others, the focal firm imitates others to develop its own documents, or the focal firm and its competitors engage in 'parallel development,' whereby the organizations strive to codify their own knowledge simultaneously (Zander and Kogut, 1995). When more competing firms are bidding for a given client contract, there thus is a higher risk that a focal team that relies heavily on documents will fail to differentiate its bid from at least some of its rivals, since the focal team and its competitors are more likely to include similar content in their bid proposals.

Second, obtaining and using large amounts of codified knowledge may hurt the team's chances of winning a highly competitive bid because the more time the team spends finding, downloading, and analyzing documents whose content does not distinguish it from competitors, the less time it will have to devote to working on the more innovative and customized parts of the bid. These opportunity costs increase the likelihood that the team will deliver a 'cookie-cutter' solution that looks much like past solutions the firm has provided to other clients or like those proposed by competitors, thus increasing the risk that the sales proposal will fall short of the client's expectations. Therefore we propose:

Hypothesis 5: With an increase in the number of competitors, an increase in the amount of codified knowledge utilized reduces the team's chances of winning the bid.

\section{Personal knowledge and number of competitors}

In contrast to the use of electronic documents, input from expert colleagues reduces the risks of developing a proposal that is indistinguishable from those of competitors, because the knowledge that these colleagues provide is likely to be more tacit and thus less readily available to competing firms than already codified knowledge (cf. Winter, 1987; Reed and DeFillippi, 1990). Moreover, because the knowledge is transferred through direct personal contacts, colleagues can tailor their advice to the particular client's situation and engage in two-way discussions to deepen the team's insight into the problem and aid the creation of distinctive solutions. Such help is important for developing a highly distinctive proposal because the client's problem is likely to be better understood, potential issues will be revealed early on, a full range of alternatives will be considered, and the team can use the input to tailor the proposal to the unique circumstances of the client.

In addition, these colleagues may agree to accompany the sales team to the meeting in which the bid is presented to the client, increasing the likelihood that the team will make a good impression on the client and helping to distinguish it from its competitors (cf. Wayne and Liden, 1995). Because it is often difficult to ascertain the inherent quality of a bid proposal, it is important for a sales team to convey such signals of competence irrespective of the written work it delivers to the prospective client. Enlisting experts who can communicate directly to external constituencies that the team is competent and can offer a highly customized proposal thus can help the team to distinguish itself from competing firms, a benefit that is likely to become more important as the number of competitors increases. Therefore we propose: 
Hypothesis 6: With an increase in the number of competitors, an increase in the amount of personal knowledge utilized increases the team's chances of winning the bid.

As for the team task experience hypotheses, these hypotheses focus only on the interactions between knowledge utilizations and task competitiveness, rather than on the net effects of utilizing codified and personal knowledge on team performance. These net effects will depend on the relative magnitudes of the main and interaction effects in a particular empirical setting.

\section{METHODS}

\section{Research site and data collection}

We tested our predictions in a study conducted at Centra Consulting (a pseudonym), a professional services firm that provides management, tax, and audit consulting services to corporate clients in a range of industries, including the energy, communications, healthcare, automotive, consumer products, and financial services industries. At the time of our study, Centra employed more than 10,000 consultants in over 100 offices across the United States, which was the country of focus for this research.

To understand how work was structured and carried out at Centra, we conducted over 30 openended interviews with partners and managers in the firm. Centra teams were involved in two types of work: developing sales proposals to bid for new client contracts and carrying out existing contracts. Client contracts included business strategy development or enterprise resource software implementation, for instance. Our research focused on those teams that were developing sales proposals with the purpose of winning a new client contract.

As was typical for firms in the management consulting industry, Centra had invested substantially in knowledge management systems to help its teams conduct their work in the 5 years prior to our study. To disseminate codified knowledge, Centra had installed an electronic database system that consisted of multiple document libraries dedicated to specific topics and industries and linked by a common search engine. The types of codified knowledge available in these documents included industry-trend analyses, benchmarking data about clients' competitors, slide presentations from previous projects, standard pricing schedules for particular tasks, and detailed documentation of Centra's best practices. In addition, Centra had also developed a knowledge-sharing culture in which it was typical for consultants to call on colleagues to obtain advice, insights, and information.

\section{Sample selection}

We used the firm's database of sales bids to draw up a list of all bids with start dates in the 3 months prior to our data collection and end dates no later than 1 month afterwards. We restricted the list to recent bids to ensure that the respondents could recall the proposal details, and to bids that were already completed or due to be completed soon so that we could gather data on their outcomes.

To limit the demands imposed on Centra's sales partners, we restricted the data collection effort by using a random number generator to draw a random sample from the 812 bids that met our selection criteria. Our final sample included a total of 259 bids, of which 120 were wins, 81 were losses, and 58 were active at the time of the study. This distribution was representative of the distribution of the original list of 812 bids in terms of project size, client industry, and topic of work. To gather data on our independent variables, we developed an original survey instrument and also used the firm's databases to gather information.

\section{Survey development and administration}

We developed the survey in collaboration with Centra managers and pretested it in interviews with five partners at the firm. These pretests indicated that the leaders of sales teams were able to respond to the survey on behalf of their teams. As selling new contracts was the primary responsibility of these leaders, preparing a sales proposal usually took most of their time during the typically brief but intense bid preparation period of 1-3 months. They therefore were well informed about what their team was working on during this period, including the extent and type of knowledge utilized. 
After the sales team leaders completed the surveys, they returned them to the firm's informationprocessing center, where their responses were collated on a confidential basis. Of the 259 surveys sent out, 191 were returned, for an overall response rate of 74 percent. The response rate was 79 percent for wins, 71 percent for losses, and 68 percent for active bids. Two months later, we followed up with the leaders of the active bids to find out whether their bids had turned into wins or losses. After determining the outcomes for the active bids and dropping nine bids for which outcomes could not be determined, our final data set included 182 bids in total, with 112 wins $(62 \%)$ and 70 losses $(38 \%)$.

\section{Testing for survey response bias}

To test for potential respondent biases in our data, we compared the 191 bids for which we received responses (including the nine that were eventually dropped) to the 68 bids for which we did not receive responses in order to examine whether there were any important differences between respondents' and non-respondents' bids that could bias our analyses. Using $t$-tests, we found no significant differences in whether the bids were competitive, their size in terms of dollar revenues, or their start dates, although respondents' bids were shorter in duration than non-respondents' bids. Because sales team leaders might be particularly reluctant to respond to surveys about recent losses, we also compared respondents to non-respondents for losses only, but the only significant difference was that respondents were more likely to return surveys about lost bids if they were larger in size, indicating that respondent bias was not a substantial concern in our sample.

\section{Testing for retrospective attribution bias}

Because a number of sales team leaders filled in the survey after the outcome of the bid was known, they may have given biased responses. Attribution theory has demonstrated that individuals tend to engage in self-serving attributions, assigning the causes of favorable outcomes to themselves and unfavorable ones to external events (e.g., Miller and Ross, 1975; Bradley, 1977). Thus, for example, sales team leaders who knew they had lost their bids may have been inclined to report greater utilization of documents and advice from colleagues because they could point to sources other than themselves as the reason for the loss. Selfserving attribution bias is not a problem in our data, however, for several reasons. First, we took great care to design the survey to avoid sales team leaders making these attributions. We first stated that the primary purpose of the survey was to understand how teams used the firm's knowledge. We then asked several questions about how they had used knowledge to prepare the bid, followed by a later section in which we asked about the outcome of the bid. The sequencing and decoupling of questions about knowledge utilization and the outcome of the bid are likely to have reduced the tendency to assign blame to the providers of knowledge when the bid was lost.

Second, we employed behavior-based scales, asking respondents to indicate the amount of codified and personal knowledge obtained (see scales below), rather than asking them about their perceptions of the usefulness of such knowledge. Reports of behaviors are less likely to produce biased data than reports of perceptions (cf. Gatignon et al., 2002).

Third, we relied on fairly senior sales partners in the firms as survey respondents. Based on our detailed understanding of the context from our field interviews, these partners were to a large extent secure in their jobs and were unlikely to report biased attributions in a survey for outside researchers who had promised confidentiality of individual responses. As prior research has shown, the tendency to engage in self-serving attribution biases does not always hold across different contexts and may be more common in artificial settings than in real-world contexts like the company we studied (e.g., Smith and Ellingson, 2002).

Fourth, to check that this potential bias was not a problem in our data set, we compared the responses for the bids for which the outcome was known at the time of the survey with those for which the team leaders did not yet know the outcome because their bids were still active at the time of the study. We found that the leaders of the 20 bids that were still active at the time the survey was returned did not make significantly different assessments about the amount of knowledge that was obtained and used from documents or people during the bid, the level of team task experience prior to the bid, or the number of competitors they faced (for descriptions of these variables, see below). Because negative attributions about knowledge resources might be especially likely 
when a bid is lost, we further tested for differences between the 52 bids that were reported as losses and the 18 bids that were reported in the survey as still active but eventually became losses. Again, we found no evidence of attribution bias in our data (see Appendix 1 for results of the $t$-tests for attribution bias).

\section{Dependent and independent variables}

\section{Contract won}

At Centra, a sales bid was classified as a win when the client signed a letter of intent to hire the firm, or as a loss when the client decided not to hire the firm. This measure of the outcome of a sales bid was unambiguous, since team leaders could not classify a proposal as sold unless they produced a letter of intent from the client stating that it had decided to hire Centra for that project. We created a dependent variable coded 1 if the team was successful in securing the contract or 0 if it was lost (contract won).

While winning a bid for a new client contract is an important measure of competitive performance in the management consulting industry, it is possible that winning a bid does not necessarily result in better financial performance for the firm. Under a 'winner's curse' scenario (Thaler, 1992), the 'winner' may win the contract but receive too little compensation for the work the firm undertakes. In particular, a potential source of bias in this study is that teams with relatively little experience in the area of the bid may win more bids by lowering their price, while more experienced teams may lose more bids because they are less prone to such mistakes. We performed several analyses to examine this possibility but found no evidence that there was a winner's curse problem in our data (see Appendix 2 for results of these supplementary analyses).

\section{Amount of codified knowledge obtained and used by the team}

To test Hypothesis 1, we measured the extent to which the sales team utilized electronic documents from the firm's database system. We asked the bid leaders to indicate on a 7-point scale (with anchors of 'no documents consulted' and 'a great number of documents consulted') their response to the following: 'To what extent did the sales team consult documents available in Centra's electronic databases for (1) the industry and company background analysis? (2) for the qualifications and value statement? (3) for the solution description? (4) for the proposal overall (all areas of the proposal and all written output, including presentations, reports, work plans, etc.)?' Respondents were likely able to assess the level of electronic documents used by the team, because the administrators of the knowledge management system routinely sent updates to the firm's partners on the level of usage of the system by various projects. We took the average of the responses to these questions to generate a continuous measure of the amount of knowledge obtained and used from electronic document databases, with a Cronbach alpha of 0.82 (amt. codified knowledge).

\section{Amount of personal knowledge obtained and used by the team}

To test Hypothesis 2, we measured the extent to which the sales teams relied on advice and information from other consultants in Centra when preparing their bid proposals. We asked each sales team leader to record the number of Centra partners and consultants who were not working on the bid who assisted the team and then to break this number down by the total hours of assistance they provided, i.e., the number of people who provided 1-2 hours, 3-5 hours, 6-10 hours, 11-20 hours, 21-40 hours, and 40-60 hours (anyone who worked more than 60 hours would be part of the team). Because sales team leaders were required to submit a list of individuals who helped on each project to the human resources department for annual performance reviews, they regularly kept track of who had helped and how much they had helped on various projects. They were thus able to respond to this question, although they may have been less well informed about individuals who provided only 1 or 2 hours of assistance. We multiplied the number of people who assisted the team by the mid-value of the hours of assistance they provided and aggregated the scores to create a continuous measure of the number of personhours of help that the team received (amt. personal knowledge). In contrast to social network measures in which respondents indicate their typical level of personal interactions irrespective of particular 
tasks (e.g., Marsden, 1990), this measure emphasizes the actual extent of help from colleagues for a given proposal.

\section{Team's level of task experience}

At Centra, sales teams could be experienced in both the approaches to particular client problems, known as 'solutions,' and in the techniques appropriate to implement those approaches, known as 'methodologies.' We asked the team leaders two questions: 'Prior to the start of this sales proposal, how much experience did the sales team have with the solution [methodologies] described in this proposal?' (7-point scales with anchors of 'no experience' and 'very extensive experience'). These questions capture the overall level of the team's experience in the area of the task, though they do not allow us to distinguish between the various ways in which this experience might have been distributed among the team members. For example, two bid leaders might have reported similar levels of task experience for one team that was composed of five moderately experienced members and another that was composed of one very experienced member and four very inexperienced members. Our measure is thus limited to the aggregate level of team experience with the requirements of the task (team experience). The Cronbach alpha for this measure is 0.86 . To test Hypotheses 3 and 4 , we multiplied the team task experience measure by the codified and personal knowledge measures (amt. codified knowledge $\times$ team experience and amt. personal knowledge $\times$ team experience $)$.

\section{Number of competitors}

To capture the competitiveness of the bidding situation that the Centra team faced, we asked the bid leader to indicate whether the bid was competitive and, if so, how many other consulting companies were involved in the bid. ${ }^{2}$ Because clients invited Centra's teams to 'bake-offs' in competitive situations, all Centra bid leaders knew whether the bid

\footnotetext{
${ }^{2}$ To address the possibility that sales teams may have confronted a few but formidable competitors, we also ran an analysis controlling for the effects of facing Centra's main competitors, namely the other large accounting-based consulting firms. We entered dummy variables for each of the four main competitors, indicating whether they were also bidding on this proposal. Because these did not alter the results, we omitted them from the main analysis.

was competitive, and they also knew how many other consulting firms had been asked to bid. ${ }^{3}$ We created a continuous measure of the level of task competitiveness by recording the number of other competing companies and entering a value of zero if the bid was not competitive (no. of competitors). To test Hypotheses 5 and 6, we created two interaction terms to capture how the effects of obtaining and using codified and personal knowledge depended on the number of competing bidders (amt. codified knowledge $\times$ no. of competitors and amt. personal knowledge $\times$ no. of competitors $)$.

\section{Control variables}

Reasons for utilizing knowledge and winning bids

It is important to control for reasons that may explain why a team utilized knowledge in the first place, as such underlying reasons may create a spurious relationship between our independent variables and the outcome of the bid. Based on our in-depth interviews in the company, we identified several such reasons and controlled for them in our models. First, teams may have had different skill levels: less skilled teams may have sought more knowledge than more skilled teams, but skill level may also have a direct impact on the chances of winning the bid. Although the sales team leaders did not attain their positions at Centra without having demonstrated skills in selling consulting services, there was likely to be some variation in the skill level or sales talent among the team leaders. We controlled for this possible source of heterogeneity in the sample by measuring the extent of a sales leader's experience in developing and selling proposals. Although sales experience is not a direct measure of sales skills, it is a good proxy for such skills because most of the sales skills at Centra were learned on the job and through apprenticeships with more senior partners. We asked the bid leaders to report the number of sales proposals that they had worked on during their tenure at Centra and entered their responses in categories (i.e., 1 if $0-10$ proposals, 2 if $11-20$ proposals, 3 if $21-50$, 4 if more than 50 proposals) as a control variable in the models (leader sales skills).

Second, larger teams may have devoted more resources to obtaining knowledge than smaller

\footnotetext{
${ }^{3}$ We asked respondents to indicate if they did not know the number of competitors, but none responded that they did not know.
} 
teams, simply because there were more team members available to take on this activity. Moreover, larger teams may have possessed a larger competence base than smaller teams, enhancing their chances of winning and thus creating a spurious relationship between the amount of knowledge utilized and the outcome of the bid. Research on groups, however, suggests that very large teams can suffer from poor coordination and process losses, resulting in inefficient expenditures of time and effort on unproductive search and transfer activities (cf. Hackman, 2002). We therefore included a variable to control for the number of Centra professionals who worked full time on the bid and also squared this variable to capture the possibility that increasing team size may enhance the chances of winning to some point, beyond which large team size may be a negative factor that reduces the chances of winning the bid (team size and team size-squared).

Third, our interviews also revealed that the firm's social capital in the form of ties with the potential client was important in understanding a sales team's level of knowledge use and its chances of winning a bid. A sales team may have needed to invest less time and effort in developing a creative proposal that demonstrated its firm's full range of competencies if the client was already working with Centra on other projects. We therefore asked the bid leader to report whether anyone at Centra was involved in an engagement for the client at the time of the proposal and coded a dichotomous variable 1 if the company was already a client of Centra, or 0 if it was not (Centra client). However, this factor must be considered in relation to the social capital held by the competition. A Centra team may have found itself in a considerably weaker competitive position if its competitors for the contract were currently working on other projects with the buying firm. To capture this possibility, we asked the bid leader to report whether any of Centra's main competitors were working on an engagement for the client company at the time of the proposal. We coded a dichotomous variable 1 if the client company was a current client of one of Centra's competitors, and 0 otherwise (competitor client).

Fourth, the firm's overall level of knowledge in the area of the bid may explain both the team's probability of winning and the extent of knowledge use by the team. Teams may have utilized more knowledge simply because there was more knowledge available, which in turn may have been a function of the overall level of task-relevant experience in the firm. This is essentially the 'knowledge stocks' argument: higher stocks of knowledge in the areas of a bid at the firm level explains why teams win or lose. To control for this possibility, we assessed the extent to which the firm had an overall level of expertise in the areas required for the particular bid by asking the respondents to indicate the extent of the firm's overall expertise on two scales: 'Prior to the start of this sales proposal, how much experience did Centra have with the solution [methodologies] described in the proposal?' (7-point scales with anchors of 'no experience' and 'very extensive experience'). The two scales were averaged to create a measure of the availability of knowledge within the firm prior to the start of the bid, with a Cronbach alpha of 0.85 (firm experience).

\section{Additional reasons for utilizing knowledge}

While these variables may explain the reasons both for utilizing knowledge and for winning the bid, our field interviews also suggested that there were two other factors that affected the extent to which a team obtained and used knowledge from databases or colleagues. The first factor identified by interviewees was the complexity or tacitness of the knowledge involved in preparing the sales proposal. Our interviews suggested that proposals that required knowledge that was highly complex or tacit were not necessarily more difficult to win, as clients appreciated the technical difficulties inherent in the task. However, the tacitness of the knowledge could explain the different amounts of electronic documents and collegial advice utilized by the team, so we controlled for this possibility by asking the bid leaders to respond to the following statements, using a 7-point scale from 1 'strongly disagree' to 7 'strongly agree:' 'Large parts of the solutions can be adequately described in reports, slides, and similar documents;' 'A consultant can acquire enough knowledge about the solutions by reading documents describing the topic;' and 'It would be very difficult to adequately express the solution in a written report.' The first two scales were reverse-coded, and responses to the three questions were averaged to create a measure of the tacitness of the knowledge required for the sales proposal, with a Cronbach alpha of 
0.64 (tacitness). Because prior research has suggested that there may be a curvilinear relationship between the tacitness of knowledge and the efficacy of its use within a firm (e.g., Rivkin, 2001), we standardized this variable and included a squared term to capture the effects of high levels of tacitness (tacitness-squared).

The other factor that was often mentioned in our field interviews was variation in time pressure among teams. Not only could time pressure affect the extent of knowledge utilization, but the costs and risks of obtaining and using knowledge were also likely to be amplified when a team was operating under intense time pressure, since the team was likely to incur greater opportunity costs from its search and transfer activities and have less time to spend on differentiating itself from competitors. From Centra's database of sales bids we recorded the start date and the close date of the bids and calculated the duration of a bid as the number of days between the start date and the close date (duration).

\section{Statistical approach and control for selection bias}

Although our variables focus on the process of preparing and winning a sales proposal in a competitive situation, restricting our analysis to only competitive bids creates a possible selection bias because it fails to account for why some bids were competitive while others were not. Specifically, Centra was awarded 67 of the 80 contracts for which it bid exclusively (84\%), but only 45 of the 102 competitive bids $(44 \%)$. To address this potential source of bias, we used two-part logit models to test our hypotheses (Manning, Duan, and Rogers, 1987). In the first stage of our analysis, the dependent variable was whether the bid was competitive or exclusive (competitive bid). From this model, we calculated the predicted probabilities of each bid becoming competitive, $p$ (competitive bid). To test our hypotheses while controlling for selection bias, we then ran second-stage models in which the dependent variable was whether the contract was won or lost, omitting all exclusive bids but including the p(competitive bid) variable as well as the independent variables described above. The second-stage models thus control for selection bias by including the effects from bids that were not competitive (Greene, 1993). Running a separate regression for sample inclusion followed by the main regression model is appropriate when the intermediate dependent variable is observed rather than estimated, and more appropriate than a Heckman selection model that uses the Mills' ratio since the dependent variable is binary rather than continuous (Manning et al., 1987). We used logit specifications for both the first-stage and the second-stage models.

We used four variables to predict the likelihood that a bid became competitive. First, a bid may have been less likely to turn competitive if the firm had a strong reputation in the area of the proposal, because buying firms were more likely to invite an exclusive bid when Centra was known to have conducted high-quality work in the area of the bid before. The bid leaders were therefore asked, 'At the time of the proposal, please rate Centra's reputation in the marketplace for this type of client work in the United States.' They responded by ranking Centra from 1 (best) to 7 (worst). We reverse-coded this self-reported measure so that the highest value corresponded to the highest ranking (reputation). ${ }^{4}$ Second, because our interviews suggested that a strong pre-existing relationship between members of the Centra team that was bidding for the contract and the buying firm could reduce the chances that a bid became competitive, we asked the bid leaders who had a prior relationship to indicate the strength of the relationship using a 7-point scale with anchors of 'a very close relationship' and 'a very distant relationship.' This scale was reverse-scored and those who did not have a prior relationship were given a score of 0 , creating a measure ranging from 0 (no relationship) to 7, 'a very close relationship' (relationship). Third, when a Centra team was already conducting a project for a client or had recently completed one, it would sometimes put together a sales proposal for additional work that would directly follow on from that project. Such extensions could significantly reduce the chances that a bid became competitive because the Centra team was already working closely with the client on related issues. We asked the sales team leaders whether the proposal was for an extension of current work and created a variable coded 1 if it was an extension or 0 if it was not (project extension). Finally, since a client may be more inclined to invite competitors to bid on larger contracts, we also included the logged first-year-sales value of the contract,

\footnotetext{
${ }^{4}$ We also ran a model with a dichotomous variable coded 1 if Centra was ranked best and 0 otherwise, but the results did not change.
} 


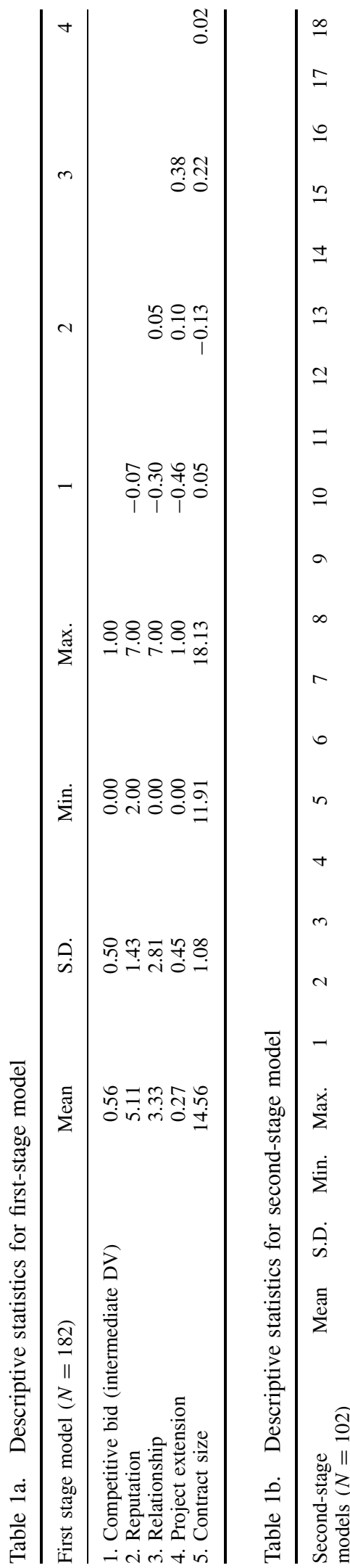

Copyright @ 2004 John Wiley \& Sons, Ltd.

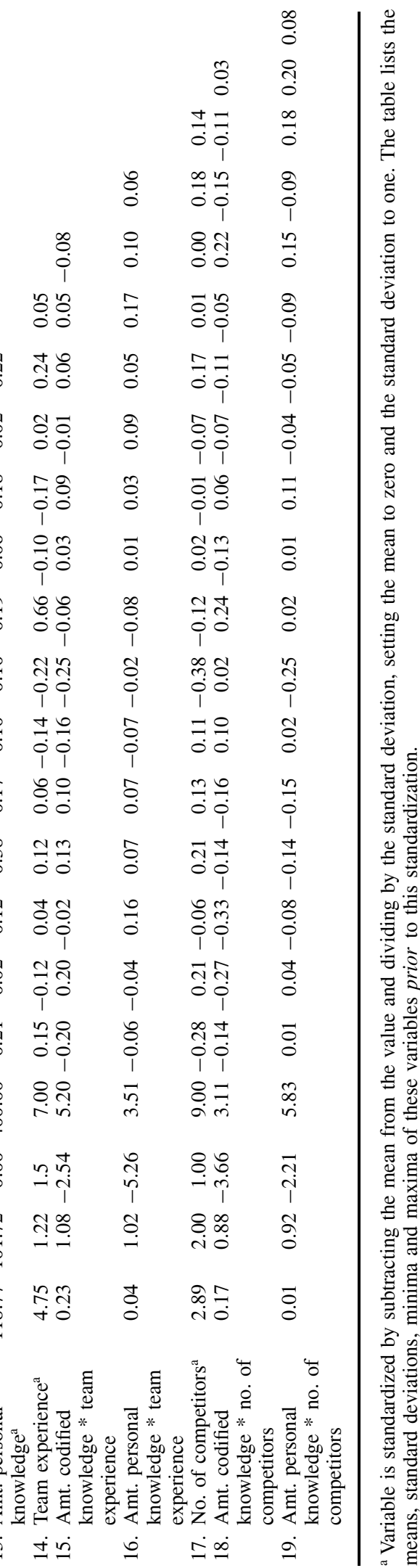

Strat. Mgmt. J., 26: 1-24 (2005) 
using information obtained through the firm's sales proposal database (contract size). To conduct our analyses, we used the logit procedure in STATA.

\section{RESULTS}

Descriptive statistics for the first- and second-stage models are reported in Table 1 . We standardized the main independent variables, by subtracting the mean and dividing by the standard deviation, to avoid high correlations between these variables and the interaction terms (Neter, Wasserman, and Kutner, 1990).

The intermediate first-stage model for predicting whether a bid becomes competitive is shown in Table 2. This model shows that a strong prior relationship between the sales team and the client significantly reduced the chances that the bid turned competitive, suggesting that the ability to win bids is partly explained by this measure of social capital: strong prior relationships seem to have acted as a barrier to entry for Centra's competitors. In addition, teams that were bidding for extensions of current projects were much less likely to find themselves facing competition.

The second-stage models predicting whether the bid was won or lost once it became competitive are reported in Table 3. Model 1 reports the baseline model including only the control variables and the codified and personal knowledge measures. Some of the results for the control variables are interesting to note.

Table 2. Logit analysis results for first-stage model (dependent variable $=$ competitive bid)

\begin{tabular}{lc}
\hline & Model \\
\hline Intercept & $-2.64(2.63)$ \\
Reputation & $-0.03(0.12)$ \\
Relationship & \\
Project extension & $-0.47(0.19)^{* *}$ \\
Contract size & $-2.00(0.44)^{* * *}$ \\
Number of observations ${ }^{\mathrm{b}}=179$ & $0.24(0.17)$ \\
Log-likelihood $^{\text {Pseudo } R^{2}}$ & \\
\hline
\end{tabular}

a Because there were missing data on this variable, it was standardized, the missing values were then set to zero, and a dummy variable for the missing observations was included in the analyses (but not reported here).

${ }^{b}$ There were missing data on several of the variables for three bids.

${ }^{*} p<0.10$; $^{* *} p<0.05$; ${ }^{* * *} p<0.01$ (two-tailed test for variable coefficients)

Copyright @ 2004 John Wiley \& Sons, Ltd.
Not surprisingly, the results for the team leader sales skills variable are positive and significant in all the models, suggesting that the bidding experience of the team leader had a positive impact of the chances of success.

However, Model 1 and the subsequent models show mixed results for team size. While the main effect is not significant, the squared term is positive and significant, suggesting that as the number of team members increased there was a non-linear increasing probability of winning the bid. Larger teams thus performed better and did not appear to suffer a productivity loss due to team size.

The firm experience variable in Model 1 shows that a sales team was more likely to win a competitive bid to the extent that the firm overall had high levels of experience in the area of the bid. This measure can be seen as a proxy for the firm's overall stock of knowledge in the area of the bid. However, its effect on the probability of winning a bid becomes non-significant when the team's level of task experience is included in subsequent models, suggesting that a stock-level view of knowledge assets has less explanatory power when task-level variables are taken into account.

Additionally, as shown in all the models in Table 3, the main effect of the tacitness of the knowledge required for the bid is significant and negative, while the squared term is significant and positive, indicating a u-shaped relationship between the degree of tacitness and team performance. These results indicate that the sales bids that required a moderate level of tacit knowledge were the most difficult to win at Centra. This finding contradicts previous research that has argued that knowledge is more valuable if it is moderately tacit (e.g., Rivkin, 2001).

Model 1 also presents the results for Hypotheses 1 and 2. The variables for the amounts of codified and personal knowledge utilized reveal that the more documents the sales team obtained and used, the less likely it was to win the bid, while the amount of advice from colleagues had no significant effect on the outcome of the bid. These findings do not support Hypothesis 1 and Hypothesis 2. In fact, the result for codified knowledge is in the opposite direction to that predicted-teams were hurt, rather than helped, by utilizing codified knowledge.

Turning to the results for the moderating effects, the effects for the team's level of task experience are introduced in Models 2-4, and the effects for 


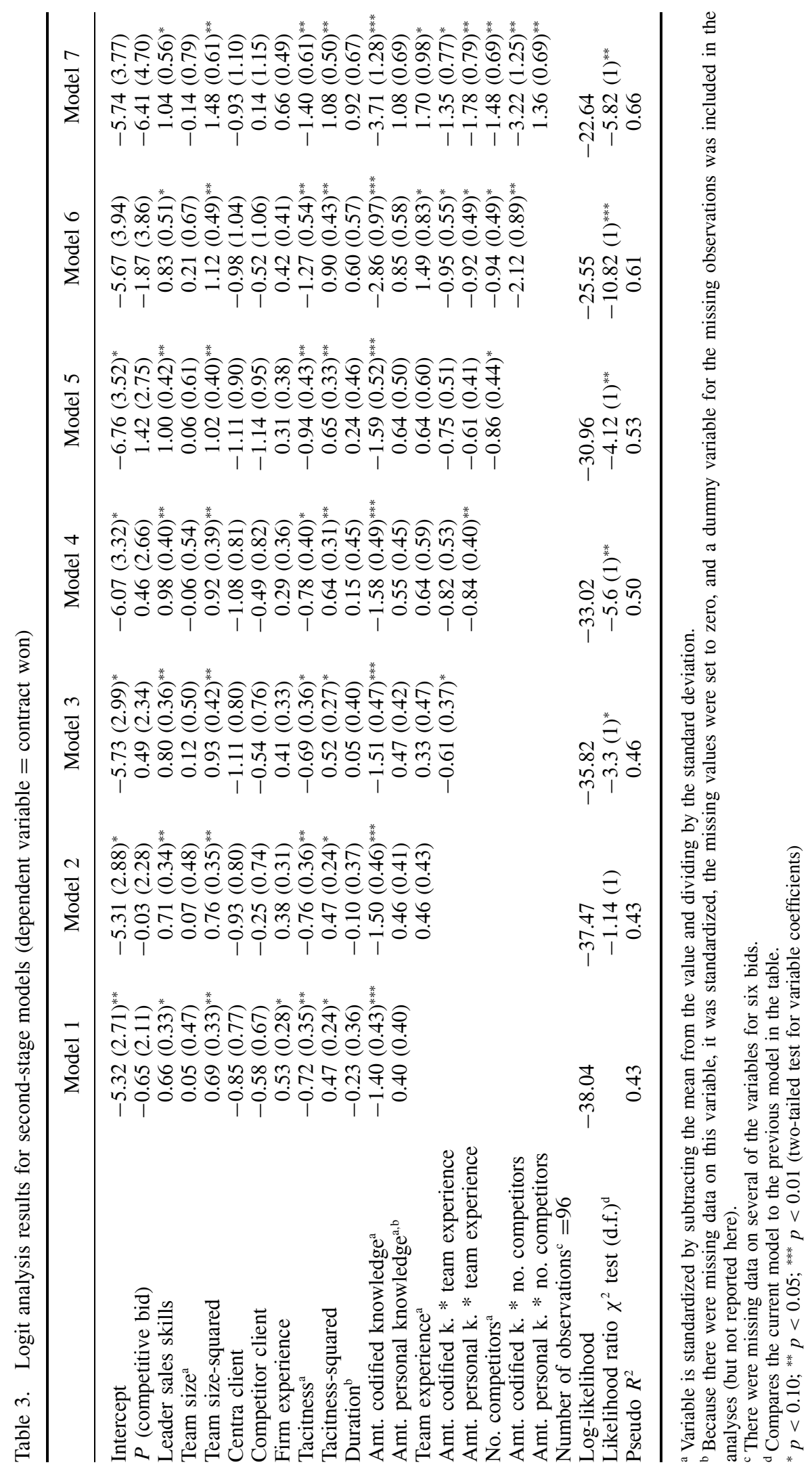


the number of competitors are introduced in Models 5-7, with Model 7 presenting the full results for all the hypotheses. ${ }^{5}$ Model 7 reveals that the interaction between the amount of codified knowledge utilized and the team's level of task experience is negative and significant. As the level of team experience increased, an increase in the amount of codified knowledge utilized by the team decreased its chance of winning the bid, lending support to Hypothesis 3. As shown in Model 7, the result is the same for the interaction between the amount of personal knowledge utilized and team experience: as the team's level of task experience increased, an increase in the amount of personal knowledge utilized by the team decreased its chances of winning the bid, supporting Hypothesis 4 .

To assess the net effects of utilizing codified or personal knowledge on the probability of wining a bid, the main and interaction effects must be combined. Using the results from Model 7, the combined effects for codified knowledge are as follows:

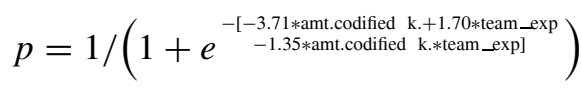

Because the main effect for the variable measuring the amount of codified knowledge use was negative (and not positive, as we had predicted in Hypothesis 1), these results reveal a 'double blow' negative effect for experienced teams: a negative main effect and a negative interaction effect with increasing levels of task experience.

Even more strikingly, when a team was very inexperienced, for example as much as 2 standard deviations below the mean level of team task experience, the strong negative main effect for codified knowledge still overwhelmed the positive magnitude of the interaction term. ${ }^{6}$ Even for very inexperienced teams, there was no net positive effect

\footnotetext{
${ }^{5}$ To test for the possibility of multicollinearity among the firm experience, team experience, and codified knowledge variables, we calculated variance inflation factors (VIFs) for Model 7 using a logit specification. High VIFs (above 10) in the variables of concern would indicate evidence of multicollinearity (Neter, Wasserman, and Kutner, 1990). The VIFs for this model were less than 3, however, indicating that multicollinearity was not a problem. We also examined the correlation matrix for the coefficients in Model 7, and again the levels of collinearity among the explanatory variables showed no cause for concern. ${ }^{6}$ When level of experience is -2 standard deviations below the mean, the equation is:
}

$$
p=1 /\left(1+e^{-[-3.71 * a m t . c o d i f i e d ~ k .+1.70 *(-2)-1.35 * a m t . c o d i f i e d ~ k . *(-2)]}\right)
$$

of utilizing codified knowledge on the chances of winning a bid.

The net effect for utilizing personal knowledge is different, as the main effect for the amount of personal knowledge utilized is positive, although not significant. Obtaining and using personal knowledge did offer net benefits to teams that were relatively inexperienced in the area of the task, since the interaction effect surpasses the main effect for teams that are 0.6 standard deviations below the mean level of experience. 7 Nevertheless, for teams that were relatively experienced, the chances of winning a bid were reduced both by utilizing more codified knowledge and by utilizing more personal knowledge.

The effects of the competition variable in Models 5-7 show that the main effect of the number of competitors is negative and significant. Teams risked losing the bid as the number of competing consulting firms increased. The interaction between the number of competitors and the amount of codified knowledge obtained and used by the team also is negative and significant, indicating that as the number of competitors increased, greater utilization of codified knowledge decreased the team's chances of winning the bid, supporting Hypothesis 5. In contrast, the interaction between the number of competitors and the amount of personal knowledge utilized by the team is positive and significant. This result indicates that as the number of competitors increased, teams that solicited more advice and input from colleagues increased their chances of winning their bids, supporting Hypothesis 6. As for the team experience interactions, these competition interaction effect results can be combined with the main effect results for utilizing codified and personal

which gives:

$$
p=1 /\left(1+e^{-[-3.71 * \text { amt.codified k. }-3.40+2.70 * \text { amt.codified } \mathrm{k}]}\right) .
$$

That is, the positive +2.70 component will not surpass the negative -3.71 component. The turning point for team experience is 2.75 standard deviations below the mean (i.e., 3.71/1.35), below which teams are so inexperienced that the net effect of utilizing codified knowledge turns positive. However, this value is outside the range in our data set (the minimum value of the standardized amount codified knowledge variable is -2.66).

${ }^{7}$ For personal knowledge, the combined main and interaction effects are given by

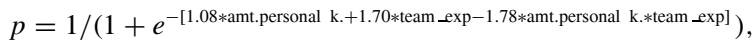
using the coefficient estimates from Model 7. 
knowledge to identify the levels of competition below which the net effects of utilizing codified knowledge may be positive (1.2 standard deviations below the mean number of competitors) and above which the net effects of utilizing personal knowledge may be negative (0.8 standard deviations below the mean number of competitors).

In summary, the results of our analyses show that the two conditions of team task experience and task competitiveness moderated the effects of utilizing codified and personal knowledge on the chances of winning a bid. Since sales teams usually must consider their level of experience and their competitive environment simultaneously, however, it is interesting to consider how these two task conditions jointly affected bid outcomes. Using the results from Model 7 in Table 3, we have plotted illustrative examples of the effects of obtaining and using codified and personal knowledge on bid outcomes for various combinations of team experience and number of competitors, as shown in Figure $2 .^{8}$ In these illustrative figures, high and

${ }^{8}$ The equation for the codified knowledge plots is:

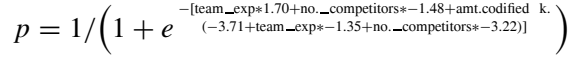
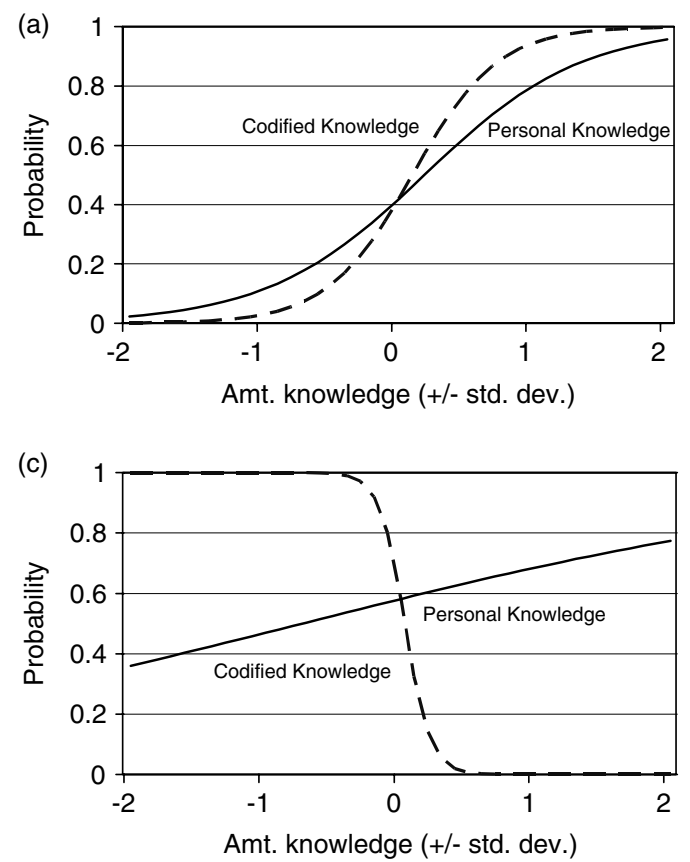

low levels of team experience and number of competitors are set at \pm 1.5 standard deviations from the mean, respectively. Figure 2(a) shows that, for a team that has a high need to learn (i.e., low team task experience) and low need to differentiate itself from competitors (i.e., low task competitiveness), utilizing both types of knowledge has a positive effect on the probability of winning the bid.

Figure 2(b) depicts the situation of a team with high needs to both learn and differentiate itself from competitors. There is a substantial positive effect of utilizing personal knowledge on the probability of winning the bid (this effect combines the two positive effects of the terms involving personal knowledge). There is a negative effect of utilizing codified knowledge, however, because the negative effect of utilizing codified knowledge in a highly competitive situation outweighs the positive effect of utilizing codified knowledge when the team is inexperienced.

The equation for the personal knowledge plots is:

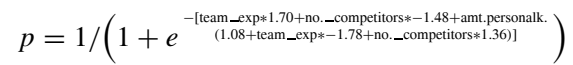
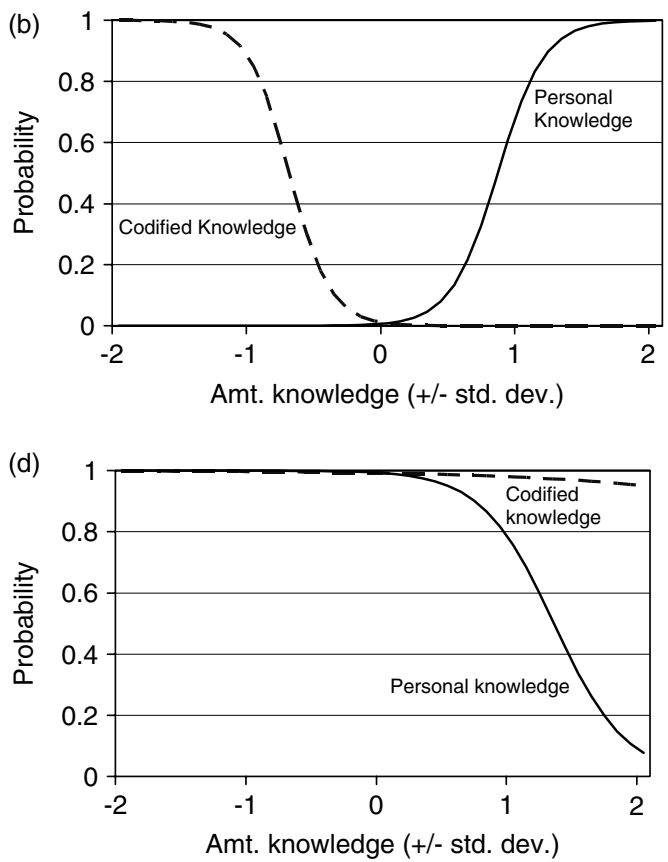

Figure 2. Plots of the effects of utilizing knowledge on the probability of winning a bid for various combinations of needs to learn and differentiate. (a) High need to learn, low need to differentiate. (b) Both high needs to learn and differentiate. (c) Low need to learn, high need to differentiate. (d) Both low needs to learn and differentiate. 
Figure 2(c) suggests that for a team with a low need to learn and high need to differentiate there is an overall positive effect of utilizing personal knowledge, because the positive effect of utilizing such knowledge in highly competitive situations outweighs the negative effect of highly experienced teams utilizing such knowledge. In contrast, there is an overall large negative effect of utilizing codified knowledge.

Finally, in Figure 2(d), which depicts the situation of a team with low needs to both learn and differentiate, both types of knowledge have a negative effect, as there is no need for a highly experienced team to learn or differentiate itself from competitors. In three out of four of these illustrative examples, therefore, the effects of obtaining and using codified knowledge are negative; only when competition is limited and the team is inexperienced in the area of the task does utilizing codified knowledge help.

\section{DISCUSSION}

The main finding of this study is that task units are not always better off obtaining and using more knowledge, since utilizing knowledge hurts task performance in some situations. Obtaining and using electronic documents was more likely to hurt a team's chances of winning a competitive bid with increasing levels of team task experience and task competitiveness. Obtaining and using personal knowledge in the form of advice from colleagues also increased the chances of losing the bid with increasing team task experience. Overall, these findings lend support to a situated performance perspective on the value of knowledge in firms that holds that task conditions moderate the effects of utilizing the firm's knowledge resources on taskunit performance.

While some of these factors may be unique to our empirical setting, the findings of this study should have implications for other organizational contexts. Although the research was limited to a setting in which utilization of the firm's knowledge resources was strongly encouraged, such work environments are increasingly common as companies invest in making their employees' expertise readily available to others in the organization through electronic database systems and firm-wide networks of experts (Sproull and Kiesler, 1991; Davenport and Prusak, 1998; Brown and Duguid,
2000). In addition to focusing on a domain in which knowledge sharing was common, this study also focused on a particular type of organizational task: preparing bids for new client contracts. Competitive bidding is a widespread practice in both the public and private sectors, and therefore an important task for many organizations (cf. Stinchcombe, 1985; Bradach and Eccles, 1989). Moreover, it is likely that the challenges of learning and differentiation faced by teams engaged in preparing competitive bids will be very similar to those faced by teams that are engaged in other project-based tasks, such as R\&D teams. Nevertheless, the relevance of the findings could usefully be examined in the context of different organizational tasks where performance is measured with different metrics, such as efficiency gains (e.g., Darr et al., 1995), product reliability (e.g., Levin, 2000), or innovativeness (e.g., Tsai, 2001).

\section{The unexpected dangers of utilizing knowledge}

One challenge posed by the results of this study is to explain the counter-intuitive main effect result, that the more codified knowledge a team utilized (regardless of the task situation), the worse its chances of winning a bid. One possibility is that obtaining and using the firm's knowledge resources was helpful only up to a point, after which it impeded performance. To test an inverted $\mathrm{u}$-shape specification, we reran the analyses using second-order terms for both codified and personal knowledge, but these second-order terms provided no evidence for this proposition. Another explanation, however, is simply that relying too much on leveraging codified knowledge led team members to depend excessively on insufficiently tailored or out-of-date prior work to guide their thinking, resulting in a bid proposal that lacked the level of development, innovation, or customization that the client expected.

Another question raised by this study is why many sales teams at Centra appear to have pursued strategies for utilizing knowledge that were detrimental to their performance, given their needs for learning and differentiation. In particular, some experienced teams drew extensively on both codified and personal knowledge from other parts of the firm, although they already had considerable expertise with the demands of the task. Other teams used electronic documents extensively when faced with a highly competitive bid situation, 
although these documents did not help to differentiate them from their competitors. Why did these teams choose such seemingly mistaken strategies for utilizing knowledge? A possible explanation is that team members felt obliged to go through the motions of consulting all the available knowledge sources because of formal incentives to utilize such resources, as well as an informal but pervasive norm of knowledge sharing in the firm. At Centra, formal incentives included evaluation of every consultant's usage of the firm's knowledge resources in their performance reviews, and these expectations were reinforced by team leaders, who routinely asked their team members whether they had checked the firm's knowledge repositories and networks for the latest information. These pressures may explain why highly experienced teams still chose to obtain and use high levels of knowledge from outside the team. In addition, teams in highly competitive situations likely felt these pressures acutely, as such situations demanded extra effort, including making sure that all of the firm's expertise was brought to bear on the bid to win against the competition. This may explain why some teams used electronic documents extensively even though this type of knowledge had a tendency to make the proposal less distinctive in situations in which distinctiveness was especially important.

\section{Implications for research on the value of knowledge}

This study has implications for research on knowledge management and the organizational capability view in strategic management. The growing literature on knowledge management has focused most of its attention to date on examining the facilitators of and barriers to knowledge transfers (e.g., Zander and Kogut, 1995; Szulanski, 1996; Gupta and Govindarajan, 2000; Schulz, 2003). Our findings suggest that this research area can be extended in important directions by focusing more attention on the net effects of knowledge flows on task performance. Research that focuses exclusively on the impediments to knowledge transfers often assumes that reduced barriers and increased knowledge flows will be beneficial for organizations. But our results demonstrate that this is not necessarily so: increased knowledge flows in the form of electronic documents may hurt competitive performance by reducing the distinctiveness of the work produced, for instance. Thus, knowledge management research can be advanced by augmenting the investigation of knowledge flows with an analysis of the effects of both the benefits and the costs of knowledge transfer for various task performance outcomes.

Considering the conditions under which sharing knowledge across subunit boundaries helps or harms task-unit performance is also important because it informs the broader question of how organizational capabilities are translated into competitive outcomes. One reason why conceptual work on the notion of organizational capabilities has tended to outpace empirical research is the difficulty of analyzing linkages between capabilities and performance (cf. Eisenhardt and Martin, 2000). This may be due in part to the problems involved in trying to measure or even define capabilities, which are significant, but it also may be due to a lack of recognition that the likelihood that such capabilities actually lead to competitive performance depends on the situation in which the capabilities are deployed. As our results demonstrate, the value of utilizing knowledge resources can vary greatly according to the learning and differentiation needs of different task units, implying that a given stock of firm-level knowledge does not confer equal value to all task units in a firm and may hurt task-unit performance if utilized inappropriately.

The situated performance perspective thus informs the broader question of how and when a firm's knowledge capabilities are translated into superior performance. In this paper, we examined two important conditions - the level of prior experience of the team with the task and the competitive intensity of the task situation-but other factors that vary within firms could also have significant effects and offer promising leads for future research. One factor that we did not consider here but that may affect the relative costs and benefits of using codified knowledge is the nature of the electronic document supply (cf. Hansen and Haas, 2001). For example, search costs may be reduced if the documents in the databases are well catalogued and readily identified by helpful keywords, and if good navigational tools are available, while transfer costs may be lower if the documents retrieved through the databases are more relevant and of higher quality because they have been preselected for inclusion in the database through a 
careful review process and edited for appropriateness of content and style. Another factor that may affect the value of utilizing knowledge from outside the team is its leadership. Some team leaders may create high expectations about the quality of the work that they expect their team to deliver, and establish a norm of discussing and questioning all information that is gathered from outside the team, but other teams might be more lax about enforcing such discipline, increasing the risks of relying excessively on past work in ways that prevent the development of a forward-thinking proposal that would capture a client's attention.

In conclusion, the situated performance perspective suggests that greater insights into the processes and effects of knowledge sharing can be gained by investigating situational factors that affect the value of knowledge resources for the performance of task units within firms. As our study shows, knowledge that is valuable in one situation may be a liability in a different situation. For subsequent strategic management research on the value of a firm's knowledge and organizational capabilities in general, this suggests that the focus should be less on how much firms know than on how they use what they know.

\section{ACKNOWLEDGEMENTS}

We thank seminar participants at Harvard Business School, INSEAD, and London Business School for helpful comments, William Simpson, James Schorr, and Kate Kellogg for help with data collection, and the Department of Research at Harvard Business School for generous research support.

\section{REFERENCES}

Ancona D, Caldwell D. 1992. Bridging the boundary: external activity and performance in organizational teams. Administrative Science Quarterly 37: 634-665.

Arrow KJ. 1974. The Limits of Organization. W. W. Norton: New York.

Athanassiou N, Nigh D. 1999. The impact of U.S. company internationalization on top management team advice networks: a tacit knowledge perspective. Strategic Management Journal 20(1): 83-92.

Bierly P, Chakrabarti A. 1996. Generic knowledge strategies in the U.S. pharmaceutical industry. Strategic Management Journal, Winter Special Issue 17: $123-135$.
Blair MM, Wallman SMH. 2001. Unseen Wealth: Report of the Brookings Task Force on Intangibles. Brookings Institution Press: Washington, DC.

Bradach JL, Eccles RG. 1989. Price, authority, and trust: from ideal types to plural forms. Annual Review of Sociology 15: 97-118.

Bradley GW. 1977. Self-serving biases in the attribution process: a reexamination of the fact or fiction question. Journal of Personality and Social Psychology 36: 56-71.

Brown JS, Duguid P. 1991. Organizational learning and communities-of-practice: toward a unified view of working, learning, and innovation. Organization Science 2(1): 40-57.

Brown JS, Duguid P. 2000. The Social Life of Information. Harvard Business School Press: Boston, MA.

Cohen WM, Levinthal DA. 1990. Absorptive capacity: a new perspective on learning and innovation. Administrative Science Quarterly 35: 128-153.

Collis DJ. 1994. How valuable are organizational capabilities? Strategic Management Journal, Winter Special Issue 15: 143-152.

Cummings JN. 2004. Work groups, structural diversity, and knowledge sharing in a global organization. Management Science 50(3): 352-364.

Daft RL, Lengel RH. 1984. Information richness: a new approach to managerial behavior and organization design. In Research in Organizational Behavior, Vol. 6, Staw BM, Cummings LL (eds). JAI Press: Greenwich, CT; 191-223.

Darr ED, Argote L, Epple D. 1995. The acquisition, transfer, and depreciation of knowledge in service organizations: productivity in franchises. Management Science 41(11): 1750-1763.

Das A. 2003. Knowledge and productivity in technical support work. Management Science 49(4): 416-431.

Davenport TH, Hansen MT. 1999. Knowledge management at Andersen Consulting. Harvard Business School, Case No. 9-499-032.

Davenport T, Prusak L. 1998. Working Knowledge: How Organizations Manage What They Know. Harvard Business School Press: Boston, MA.

DeCarolis DM, Deeds DL. 1999. The impact of stocks and flows of organizational knowledge on firm performance: an empirical investigation of the biotechnology industry. Strategic Management Journal 20(10): 953-968.

Dewey J. 1938. Logic: The Theory of Inquiry. Holt: New York.

Dierickx I, Cool, K. 1989. Asset accumulation and sustainability of competitive advantage. Management Science 35: 554-571.

Eisenhardt KM, Martin JA. 2000. Dynamic capabilities: what are they? Strategic Management Journal, Special Issue 21: 1105-1121.

Gatignon H, Tushman ML, Smith W, Anderson P. 2002. A structural approach to assessing innovation: construct development of innovation locus, type, and characteristics. Management Science 48(9): 1103-1122. 
Glazer R. 1998. Measuring the knower: toward a theory of knowledge equity. California Management Review 40(3): 175-194.

Grant RM. 1996. Prospering in dynamically competitive environments: organizational capability as knowledge integration. Organization Science 7: 375-387.

Greene WH. 1993. Econometric Analysis (2nd edn). Macmillan: New York.

Gupta AK, Govindarajan V. 2000. Knowledge flow within multinational corporations. Strategic Management Journal 21(4): 473-496.

Hackman JR. 2002. Leading Teams: Setting the Stage for Great Performances. Harvard Business School Press: Boston, MA.

Hansen MT. 1999. The search-transfer problem: the role of weak ties in sharing knowledge across organization subunits. Administrative Science Quarterly 44: $82-111$.

Hansen MT, Haas MR. 2001. Competing for attention in knowledge markets: electronic document dissemination in a management consulting company. Administrative Science Quarterly 46: 1-28.

Hansen MT, Nohria N, Tierney T. 1999. What's your strategy for managing knowledge? Harvard Business Review 77(2): 106-116.

Hargadon A, Sutton RI. 1997. Technology brokering and innovation in a product development firm. Administrative Science Quarterly 42: 716-749.

Huber GP. 1991. Organizational learning: the contributing processes and literatures. Organization Science 2(1): $88-115$.

Huber GP, Daft RL. 1987. The information environments of organizations. In Handbook of Organizational Communication, Jablin FM, Putnam LL, Roberts KH, Porter LW (eds). Sage: Beverly Hills, CA; 130-164.

James W. 1963 (1910). Pragmatism and Other Essays. Washington Square Press: New York.

Kogut B, Zander U. 1992. Knowledge of the firm, combinative capabilities, and the replication of technology. Organization Science 3: 383-397.

Lave J, Wenger E. 1993. Situated Learning: Legitimate Peripheral Participation. Cambridge University Press: New York.

Leonard D. 1995. Wellsprings of Knowledge: Building and Sustaining the Source of Innovation. Harvard Business School Press: Boston, MA.

Lev B. 2001. Intangibles: Management, Measurement, and Reporting. Brookings Institution Press: Washington, DC.

Levin DZ. 2000. Organizational learning and the transfer of knowledge: an investigation of quality improvement. Organization Science 11: 630-647.

Manning WG, Duan N, Rogers WH. 1987. Monte Carlo evidence on the choice between sample selection and two-part models. Journal of Econometrics 35: 59-82.

Marsden PV. 1990. Network data and measurement. Annual Review of Sociology 16: 435-463.

McEvily SK, Chakravarthy B. 2002. The persistence of knowledge-based advantage: an empirical test for product performance and technological knowledge. Strategic Management Journal 23(4): 285-305.
Miller ST, Ross M. 1975. Self-serving biases in the attribution of causality: fact or fiction? Psychological Bulletin 82: 93-118.

Nelson RR, Winter SG. 1982. An Evolutionary Theory of Economic Change. Belknap Press: Cambridge, MA.

Neter J, Wasserman W, Kutner MH. 1990. Applied Linear Statistical Models (3rd edn). Irwin: Homewood, IL.

Okhuysen GA, Eisenhardt KM. 2002. Integrating knowledge in groups: how formal interventions enable flexibility. Organization Science 13(4): 370-386.

Orlikowski W. 2002. Knowing in practice: enacting a collective capability in distributed organizing. Organization Science 13(3): 249-273.

Orr J. 1996. Talking About Machines: An Ethnography of a Modern Job. Cornell University Press: Ithaca, NY.

Pentland BT. 1992. Organizing moves in software support hot lines. Administrative Science Quarterly 37: 527-548.

Pfeffer J, Sutton RI. 1999. The Knowing-Doing Gap: How Smart Companies Turn Knowledge into Action. Harvard Business School Press: Boston, MA.

Reagans R, McEvily B. 2003. Network structure and knowledge transfer: the effects of cohesion and range. Administrative Science Quarterly 48: 240-267.

Reed R, DeFillippi RJ. 1990. Causal ambiguity, barriers to imitation, and sustainable competitive advantage. Academy of Management Review 15(1): 88-102.

Rivkin J. 2001. Reproducing knowledge: replication without imitation at moderate complexity. Organization Science 12(3): 274-293.

Rorty R. 1979. Philosophy and the Mirror of Nature. Princeton University Press: Princeton, NJ.

Schulz M. 2003. Pathways of relevance: exploring inflows of knowledge into subunits of multinational corporations. Organization Science 14(4): 440-459.

Skandia. 1998. Human Capital Transformation: Intellectual Capital Prototype Report. Supplement to the Annual Report. Skandia Insurance Company: Stockholm, Sweden.

Smith BD, Ellingson JE. 2002. Substance versus style: a new look at social desirability in motivating contexts. Journal of Applied Psychology 87: 211-219.

Sproull L, Kiesler S. 1991. Connections: New Ways of Working in the Networked Organization. MIT Press: Cambridge, MA.

Stinchcombe A. 1985. Contracts as hierarchical documents. In Organization Theory and Project Management, Stinchcombe A, Heimer C (eds). Norwegian University Press: Bergen, Norway; 121-171.

Sutton RI, Hargadon A. 1996. Brainstorming groups in context: effectiveness in a product design firm. Administrative Science Quarterly 41: 685-718.

Szulanski G. 1996. Exploring internal stickiness: impediments to the transfer of best practice within the firm. Strategic Management Journal, Winter Special Issue 17: $27-43$.

Szulanski G. 2000. The process of knowledge transfer: a diachronic analysis of stickiness. Organizational Behavior and Human Decision Processes 82(1): 9-27. 
Teece DJ. 1986. Profiting from technological innovation: implications for integration, collaboration, licensing, and public policy. Research Policy 15: 285-305.

Teece DJ, Pisano G, Shuen A. 1997. Dynamic capabilities and strategic management. Strategic Management Journal 18(5): 509-533.

Thaler RH. 1992. The Winner's Curse: Paradoxes and Anomalies of Economic Life. Free Press: New York.

Tsai WP. 2001. Knowledge transfer in intraorganizational networks: effects of network position and absorptive capacity on business unit innovation and performance. Academy of Management Journal 44(5): 996-1004.

Tyre MJ, von Hippel E. 1997. The situated nature of adaptive learning in organizations. Organization Science 8: 71-83.

Uzzi B. 1997. Social structure and competition in interfirm networks: the paradox of embeddedness. Administrative Science Quarterly 42: 35-67.
Wayne SJ, Liden RC. 1995. Effects of impression management on performance ratings: a longitudinal study. Academy of Management Journal 38(1): 232-260.

Winter SG. 1987. Knowledge and competence as strategic assets. In Teece DJ (ed.), The Competitive Challenge. Ballinger: Cambridge, MA; 159-184.

Winter SG, Szulanski G. 2001. Replication as strategy. Organization Science 12(6): 730-743.

Zander U, Kogut B. 1995. Knowledge and the speed of transfer and imitation of organizational capabilities: an empirical test. Organization Science 6: 76-92. 


\section{APPENDIX 1: RESULTS OF $T$-TESTS FOR POTENTIAL ATTRIBUTION BIASES}

Table A1. Mean differences between active bids and bids reported as won or lost

\begin{tabular}{|c|c|c|c|c|c|c|c|}
\hline \multirow[t]{2}{*}{ Variable } & \multicolumn{3}{|c|}{ Active bids } & \multicolumn{3}{|c|}{ Won/lost bids } & \multirow[t]{2}{*}{$t$} \\
\hline & $n$ & Mean & S.D. & $n$ & Mean & S.D. & \\
\hline Amt. codified knowledge & 20 & 3.96 & 1.26 & 169 & 3.64 & 1.54 & -1.06 \\
\hline Amt. personal knowledge & 20 & 114.98 & 183.07 & 171 & 165.16 & 359.37 & 1.02 \\
\hline Team experience & 20 & 4.65 & 1.22 & 171 & 4.86 & 1.26 & 0.73 \\
\hline No. of competitors & 13 & 3.77 & 2.35 & 93 & 2.83 & 2.88 & -1.31 \\
\hline
\end{tabular}

Table A2. Mean differences between active bids that became losses and bids reported as lost

\begin{tabular}{|c|c|c|c|c|c|c|c|}
\hline \multirow[t]{2}{*}{ Variable } & \multicolumn{3}{|c|}{ Active-lost bids } & \multicolumn{3}{|c|}{ Lost bids } & \multirow[t]{2}{*}{$t$} \\
\hline & $n$ & Mean & S.D. & $n$ & Mean & S.D. & \\
\hline Amt. codified knowledge & 18 & 4.08 & 1.27 & 52 & 4.17 & 1.45 & 0.25 \\
\hline Amt. personal knowledge & 18 & 124.42 & 190.91 & 52 & 153.81 & 169.14 & 0.58 \\
\hline Team experience & 18 & 4.58 & 1.19 & 52 & 4.64 & 1.13 & 0.19 \\
\hline No. of competitors & 13 & 3.77 & 2.35 & 43 & 3.09 & 1.70 & -0.96 \\
\hline
\end{tabular}

\section{APPENDIX 2: TESTING FOR A POTENTIAL WINNER'S CURSE PROBLEM}

To investigate the possibility that a winner's curse was operating at Centra Consulting, we ran two sets of supplementary analyses. First, we tested whether teams with high levels of task experience were more likely than inexperienced teams to refuse to lower their price to win a competitive bid - that is, to walk away from the bid. In the survey, we asked leaders who lost their bids to rank the most important reasons why they lost. One of the ten possible reasons was 'Centra's price was too high.' If a winner's curse were operating, more experienced teams should have been more likely to give this as a reason for losing than less experienced teams, because they were more willing to lose the bid than to lower Centra's price in order to win it. Comparing the task experience levels of teams that gave this as one of their two top reasons for losing the bid (mean experience $=4.8, n=$ 17) and those that did not (mean experience $=$ $4.5, n=31$ ) showed no significant differences $(t=-0.8, p>|t|=0.4)$. Second, we tested the effects of team experience on the tendency to lower the price of a bid in order to win a new client contract. When clients invited Centra to submit a
Table A3. Logit results for winner's curse analysis (dependent variable: $1=$ final price lower than baseline

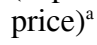

\begin{tabular}{|c|c|}
\hline & Model \\
\hline Intercept & $0.69(1.88)$ \\
\hline Leader sales skills & $-0.41(0.64)$ \\
\hline Team size ${ }^{\mathrm{b}}$ & $1.88(0.17)$ \\
\hline Team size-squared & $-0.20(0.57)$ \\
\hline Tacitness $^{\mathrm{b}}$ & $0.16(0.61)$ \\
\hline Tacitness-squared & $-0.51(0.59)$ \\
\hline Amt. codified knowledge ${ }^{b}$ & $0.72(1.10)$ \\
\hline Amt. personal knowledge ${ }^{b}$ & $-1.55(1.25)$ \\
\hline Team experience ${ }^{\mathrm{b}}$ & $-0.89(0.86)$ \\
\hline Amt. codified k. $*$ team experience & $-0.29(0.85)$ \\
\hline Amt. personal k. * team experience & $-0.42(0.70)$ \\
\hline No. competitors ${ }^{\mathrm{b}}$ & $0.81(1.30)$ \\
\hline Amt. codified k. * no. competitors & $2.02(1.53)$ \\
\hline Amt. personal k. * no. competitors & $-0.65(1.79)$ \\
\hline \multicolumn{2}{|l|}{ Number of observations $^{c}=45$} \\
\hline Log-likelihood & -15.04 \\
\hline Pseudo $R^{2}$ & 0.39 \\
\hline
\end{tabular}

${ }^{a}$ Winner's curse model shown here includes only variables that were significant in the main analyses, to enable model convergence with smaller $n$. Coefficient estimates shown with standard errors in parentheses.

${ }^{\mathrm{b}}$ Variable is standardized by subtracting the mean from the value and dividing by the standard deviation.

${ }^{c}$ This model was run on the 45 competitive bids that Centra won, because it is only these bids to which the winner's curse scenario applies. 
bid, Centra partners usually estimated what their contracts were worth according to the scope of the work and entered this initial price as a baseline in the firm's sales database. We obtained this number from the database and measured the deviation from this initial price baseline by asking team leaders who won their bids to report whether the final price of the contract they won was under, equal to, or above the baseline price (this information was not available for teams that had not won their contract as no final price was agreed on). We performed a logit analysis in which the dependent variable was coded 1 if the team won the bid with a price that was less than was initially expected, or 0 if the team won the bid with a price that was equal to or higher than the baseline. As shown in Table A3, the results indicated that teams with less task experience were not significantly more likely to win bids with a lower price than the baseline price. In short, the results of these supplementary analyses indicated that there was no evidence that a winner's curse was operating at Centra at the time of our study. This risk may have been avoided in part because the firm imposed clear guidelines on acceptable levels for project billings to prevent teams from conceding too much on price, and in part because Centra was operating in a booming industry when this study was conducted (1997-1999). As a result, teams competed primarily on the quality of their proposals, and the pressures to reduce price to win bids were not as high as may be expected when the industry is experiencing a downturn. 